\title{
SENTIDO DO TRABALHO E A ESCOLHA PELA VIDA NA CASERNA PARA MILITARES DO EXÉRCITO BRASILEIRO
}

\section{MEANING OF WORK AND THE CHOICE FOR LIFE IN CASERN FOR MILITARY OF THE BRAZILIAN ARMY}

MARCELA GIULIANI DENARDIN

Filiação: Universidade Federal de Santa Maria

Titulação: Mestra em Administração

Orcid: https://orcid.org/0000-0002-6325-6746 / E-mail: marceladenardin@gmail.com

Rua Cesar Trevisan, 1333 - Santa Maria, RS

JÉSSICA DA SILVA MACIEL

Filiação: Universidade Federal de Santa Maria

Titulação: Mestra em Administração

Orcid: https://orcid.org/0000-0002-6472-7845 / E-mail: jessicadsmaciel@gmail.com

LUIS FELIPE DIAS LOPES

Filiação: Universidade Federal de Santa Maria

Titulação: Doutor em Engenharia de Produção

Orcid: https://orcid.org/0000-0002-2438-0226 / E-mail: Iflopes67@yahoo.com.br

\section{LUCIANA DAVI TRAVERSO}

Filiação: Universidade Federal de Santa Maria

Titulação: Doutora em Administração

Orcid: https://orcid.org/0000-0002-4641-1038 / E-mail: luciana.traverso@ufsm.br

Submissão: 08/03/2021. Revisões: 26/05/2021; 25/07/2021; Aceite: 29/10/2021. Publicação: 01/02/2022. DOI: http://dx.doi.org/10.22277/rgo.v15i1.6152

\section{RESUMO}

Objetivo: O objetivo deste estudo foi compreender os sentidos do trabalho para militares de carreira do Exército Brasileiro.

Método/abordagem: A pesquisa caracterizou-se a partir do método quantitativo. Para a coleta de dados, aplicou-se o instrumento Escala do Trabalho com Sentido, proposta por Bendassolli e Borges-Andrade (2015), em 166 servidores militares de carreira do Exército Brasileiro. Os dados foram analisados a partir da estatística descritiva.

Principais resultados: Como principais resultados, percebeu-se que os militares veem elevado sentido em seus trabalhos, com médias altas em todos os indicadores, com destaque para aqueles concernentes à qualidade das relações de trabalho. Em relação à comparação entre servidores, foram constatadas maiores médias na percepção do sentido do trabalho de oficiais em relação a praças.

Contribuições metodológicas / sociais / gerenciais: Os esforços empenhados na pesquisa podem se constituir em benefícios para o Exército Brasileiro, considerando que a compreensão sobre a percepção do sentido do trabalho para os militares pode servir como

Este é um artigo publicado em acesso aberto (Open Access) sob a licença Creative Commons Attribution, que permite uso, distribuição e reprodução em qualquer meio, sem restrições desde que o trabalho original seja corretamente citado. 
base para desenvolver ações de melhoria no trabalho, especialmente no que tange à diferença entre oficiais e praças. Pelo fato de o Exército ser uma instituição importante para a garantia da soberania e segurança nacionais, melhorar a forma pela qual seus recursos públicos, inclusive humanos, são empregados, é garantir uma Administração Pública de melhor qualidade para a sociedade.

Originalidade / relevância: O presente artigo destaca-se por ser uma das poucas pesquisas organizacionais realizadas com o Exército Brasileiro, instituição que é importantíssima para a soberania nacional. Apesar de algumas limitações, a exemplo da falta de subjetividade da aplicação de um instrumento como a Escala do Trabalho com Sentido, pode-se perceber diversos aspectos que perpassam o sentido que o militar do Exército dá ao seu trabalho.

Palavras-chave: Sentido do trabalho. Militar. Exército brasileiro.

\section{ABSTRACT}

Purpose: The purpose of this study was to understand the meanings of the work for the Brazilian Army's career military.

Method/approach: The research was characterized using the quantitative method. For the data gathering, the Meaningful Work Scale proposed by Bendassolli and Borges-Andrade (2015) was applied. The data were analyzed using the descriptive statistic.

Main findings: As main results, it was perceived that the military see their jobs as highly meaningful, especially what regards to the quality of work relationships.

Methodological / social / managerial contributions: The efforts made in the research can constitute benefits for the Brazilian Army, considering that, understanding how military perceive their contributions, actions can be developed to improve the work environment and productivity. As the Army is an important institution for guaranteeing national sovereignty and security, improving the way its public resources, including human, are employed, is a way to guarantee a better-quality Public Administration for the whole society.

Originality / relevance: This article stands out for being one of the few organizational surveys carried out with the Brazilian Army, an institution that is extremely important for national sovereignty. Despite some limitations, such as the lack of subjectivity in the application of an instrument such as the Meaningful Work Scale, it was possible to perceive several aspects that permeate the meaning that the Army military gives to his work.

Keywords: Meaning of work. Military. Brazilian army.

\section{INTRODUÇÃO}

Para Luchetti (2006, p. 9), "estudar as Forças Armadas, mais especificamente o Exército, é uma forma de resgatar a formação do próprio Estado Brasileiro". Neste contexto, o Exército Brasileiro (EB), instituição que atua na Defesa Nacional, contribui fortemente para garantir a soberania nacional, os poderes constitucionais e a lei e a ordem, com o objetivo de salvaguardar os interesses nacionais e contribuir com o desenvolvimento nacional e o bemestar social (Exército Brasileiro [EB], n. d.). Para a concretização de tais objetivos, os servidores militares possuem características que os distinguem de grande parte da sociedade: renunciam a determinados direitos para servir integralmente à instituição; para isso, dedicam aspectos 
não somente da vida profissional, mas também da vida pessoal, como o convívio familiar, para que o interesse público tenha precedência sobre os interesses particulares (Santos, 2018).

O militar, portanto, vive em "mundo dentro do mundo, distinto do mundo que o circunda". Apesar de sua secularidade, o Exército não pode se manter ileso das características da modernidade, sendo difícil observar de que maneira ele tem sido influenciado pelos comportamentos de seus integrantes, que vivem submersos em uma sociedade que contribui não somente com seus valores em transformação, mas da transformação como valor (Santos, 2018, p. 259).

Frente a uma aparente contradição de valores, em que os militares se encontram, concomitantemente, em um polo laboral conservador, hierárquico e tradicional e em um polo social progressista e com maior abertura à mudança, é importante analisar as percepções destes servidores no que tange aos seus trabalhos, tendo em vista a realidade social da modernidade ocidental e a realidade institucional do Exército Brasileiro (Santos, 2018). Estudar o comportamento dos militares, porém, não é algo usual nas ciências sociais e humanas. Pelo contrário: "os militares são pouco conhecidos, às vezes estranhos até para o universo civil" (Leirner, 1997, p. 9). A falta de conhecimento acerca das funções institucionais do Exército Brasileiro provoca uma visão deturpada e, eventualmente, a interpretação errônea de determinadas ações (Silva, 2019).

Observar os sentidos do trabalho é um esforço bastante enriquecedor, pois entender o que leva um indivíduo a optar por essa caminhada e o que ele entende por sua carreira é basilar para o estudo do comportamento organizacional, considerando, ainda, as peculiaridades deste meio. $O$ trabalho se constitui em condição fundamental para a existência humana e social, bem como para manter a sociabilidade humana (Sousa, 2012; Rohm \& Lopes, 2015). Em um cenário de pós-modernidade, todavia, o trabalho apresenta-se como único fundamento da vida de alguns indivíduos, de forma que buscam nele o sentido de suas vidas (Rohm \& Lopes, 2015). Tal característica torna-se ainda mais aparente quando se observa o contexto militar, de total abnegação e disciplina. Dada a importância do trabalho na atualidade, estudos acerca dos sentidos deste vem crescendo exponencialmente.

Morin (1996) entende que o sentido do trabalho é composto por uma estrutura com três aspectos: a) significado - valor atribuído pelo indivíduo a sua atividade laboral; b) orientação - o que o trabalhador espera e busca em seu trabalho; e c) coerência - maneira harmônica de observar a relação indivíduo-trabalho. Além das concepções individuais, o trabalho é visto, também, por terceiros, pessoas e/ou grupos que não fazem parte da relação de trabalho. Esta abordagem faz referência ao significado do trabalho, constructo que aborda a representação social do trabalho em três níveis: individual, grupal e social (Tolfo \& Piccinini, 2007).

Tendo em vista as diversas possibilidades de inserção no Exército Brasileiro, que serão abordadas com maior profundidade ao longo deste estudo, voltou-se o estudo para aqueles militares que optaram voluntariamente pela vida na caserna, e não por força do serviço militar obrigatório instituído no Estado Brasileiro, para que se possa estudar os constructos supracitados sem a influência de fatores externos de motivação para o ingresso nas Forças Armadas, como a obrigatoriedade legal.

Com base no exposto, o objetivo central deste trabalho foi de compreender os sentidos do trabalho para militares de carreira do Exército Brasileiro. Como objetivos específicos, buscou-se: a) descrever o perfil sociodemográfico dos respondentes; b) verificar a manifestação das variáveis da Escala do Sentido do Trabalho (Bendassolli \& Borges-Andrade, 
2011), para os militares pesquisados; e c) distinguir o Sentido do Trabalho para oficiais e praças do Exército Brasileiro.

A partir destes objetivos, o presente artigo está estruturado em mais 5 seções, além destas noções introdutórias. A segunda seção apresenta o referencial teórico que orientou os estudos acerca do sentido do trabalho e um breve histórico do Exército Brasileiro e as explicações sobre o ingresso nesta instituição. Em seguida, foram abordados os procedimentos metodológicos que nortearam esta pesquisa. Na quarta seção, foi realizada a apresentação dos dados obtidos e, em sequência, a discussão acerca deles. Na última seção, abordaram-se as conclusões percebidas pelos autores.

\section{REVISÃO DA LITERATURA}

A conceituação do trabalho é um ponto de partida essencial para o estudo do sentido e significado do trabalho, que pode ser abordado por múltiplas disciplinas e perspectivas teóricas (Tolfo \& Piccinini, 2007). O trabalho pode ser concebido, de maneira genérica, como a capacidade de transformação da natureza para que as necessidades humanas sejam atendidas (Marx, 1993). O trabalho consiste em uma relação entre homem e natureza, por meio da qual se concretiza o ato de designar significado à natureza, e quanto mais completa a relação entre sujeito, trabalho e significado, maior o prazer do trabalhador (Codo, 1997).

As pesquisas iniciais referentes ao sentido do trabalho são atribuídas a Hackman e Oldhan (1975). Para os autores, um trabalho com sentido é importante, útil e legítimo para o trabalhador. Tendo em vista a concepção de Hackman e Oldhan (1975), o sentido de trabalho foi definido por Morin (1996) como uma estrutura afetiva composta por três fatores: significado, referente às representações do sujeito acerca de suas tarefas; orientação, relacionada à sua inclinação para trabalhar, o que ele almeja e guia suas atitudes; e coerência, que consiste na harmonia esperada de sua relação com o trabalho exercido.

Os sentidos no trabalho ligam-se diretamente aos anseios individuais acerca da ação executada, o que legitima que tal indivíduo fale sobre os benefícios e malefícios para si da função desempenhada (Mendes \& Santos, 2013). Morin e Aubé (2009) salientam que a temática do sentido no trabalho trata-se de interrogar a maneira como a concepção do indivíduo é elaborada, a orientação e coerência do trabalho para o indivíduo e sua percepção dos valores subjacentes. Algumas características que definem o sentido do trabalho são a utilidade de uma atividade executada para a organização, a autorrealização, satisfação, sentimento de evolução pessoal, autonomia para execução das tarefas e, também, o significado (Meaning of Work International Research Team, 1987).

A maneira como o trabalho é organizado influencia consideravelmente o sentido do trabalho para os indivíduos, visto que tal organização altera os comportamentos para que os trabalhadores tenham atitudes positivas em relação às funções executadas, em relação à organização e a eles mesmos (Morin, 2001). A autora comenta ainda que essa organização deve proporcionar aos trabalhadores a realização de atividades com sentido, a prática e desenvolvimento de competências, o desenvolvimento de seu julgamento e livrearbítrio, e a percepção do quanto seu desempenho evolui.

Para que um trabalho possua sentido, quem o realiza deve saber para onde tal trabalho conduz, sendo essencial que os objetivos sejam claros, valorizados e que o resultado seja valorizado também por quem executa o trabalho (Morin, 2001). 0 trabalho com sentido permite que o trabalhador conheça melhor sua atividade, viabilizando que as organizações atinjam a eficácia sem a realização constante de reforços ao trabalhador, com medidas 
motivacionais que o estimulem a ter um melhor desempenho (Morin, 2001; Oliveira, Piccinini, Fontoura, \& Schweig, 2004). Oliveira, Piccinini, Fontoura e Schweig (2004) ressaltam que um trabalho com sentido possui objetivos bem definidos, com resultado valorizado por quem o realiza, possibilitando autonomia na maneira que as atividades são gerenciadas e beneficiando o uso de competências próprias dos trabalhadores para consecução dos desafios envolvidos na tarefa.

Dejours (1987) argumenta que o trabalho deve fazer sentido para o próprio indivíduo, seus pares e a sociedade. Assim, para além das contribuições na construção de algo útil para a sociedade e seus membros, o sentido do trabalho possibilita a construção da identidade pessoal e social do trabalhador em função das atividades efetuadas, possibilitando que se identifique com o que é realizado por ele (Tolfo \& Piccinini, 2007).

Dentre as infinitas possibilidades de trabalhos que a vida moderna proporciona, está o trabalhador militar. Nesse viés, a próxima seção será responsável por abordar a função do militar do Exército Brasileiro e as formas de ingresso na instituição.

\subsection{A FUNÇÃO DO MILITAR DO EXÉRCITO BRASILEIRO}

Conforme os registros históricos do EB, a instituição surge na Batalha dos Guararapes, ano de 1648, em que os então defensores do Império Português derrotaram as tropas holandesas e puseram fim ao chamado "Brasil Holandês". Entretanto, oficialmente, considerase como marco inicial a independência do país (1822), já que, a partir deste momento, as tropas passaram a ser formadas por cidadãos a serviço do Brasil - e não mais do país colonizador, Portugal.

Neste contexto, Tavares (1985) afirma que a Independência não alterou na sua substância intrínseca da instituição, importando, apenas, em transferir os objetivos da Coroa Portuguesa - a saber, defender e colonizar - para o governo da nova pátria, que passa a ter competência, admissibilidade e direito de defender-se e colonizar-se. Dois anos após a independência, O EB foi oficializado legalmente pela primeira vez, com o advento da Constituição de 1824.

Ainda, pode-se sublinhar alguns marcos históricos a exemplo da participação na Guerra do Paraguai, que, apesar da falta de suficientes efetivos, armamentos, organização e até instrução militar, obteve êxito, através do esforço de grandes figuras militares, como os generais Osório e Caxias, e do patriotismo que fez com que fossem criados sessenta corpos de voluntários, em um esforço nacional considerável (Magalhães, 1998, p. 294). Por fim, é salutar ressaltar algumas ações realizadas pelo EB na contemporaneidade, a exemplo de sua participação em missões de paz como as ocorridas na Angola (1995-1997) e no Haiti (20042017) e em missões de Garantia da Lei e da Ordem (GLO), que correspondem a ordens expressas da Presidência da República para manutenção da lei e da ordem. Foi o caso das ações de pacificação de determinadas comunidades na cidade do Rio de Janeiro, do apoio em grandes eventos como a Jornada Mundial da Juventude (2013), a Copa do Mundo (2014) e os Jogos Olímpicos (2016), e da Operação Acolhida, realizada desde 2018 na fronteira do Brasil com a Venezuela para receber os refugiados e migrantes venezuelanos que ingressam no Brasil.

Há, no EB, uma forte hierarquia, que pode ser observada na Figura 1. Conforme a Figura 1, há cinco categorias de militares: graduados, oficiais subalternos, oficiais intermediários, oficiais superiores e oficiais generais (EB, 2019c). Uma primeira alternativa para o ingresso nas fileiras do Exército Brasileiro é o serviço militar obrigatório, previsto no 
art. 143 da Constituição Federal Brasileira de 1988, que dispõe: "o serviço militar é obrigatório nos termos da lei" (Brasil, n.d.).

Figura 1

Descrição da hierarquia no Exército Brasileiro
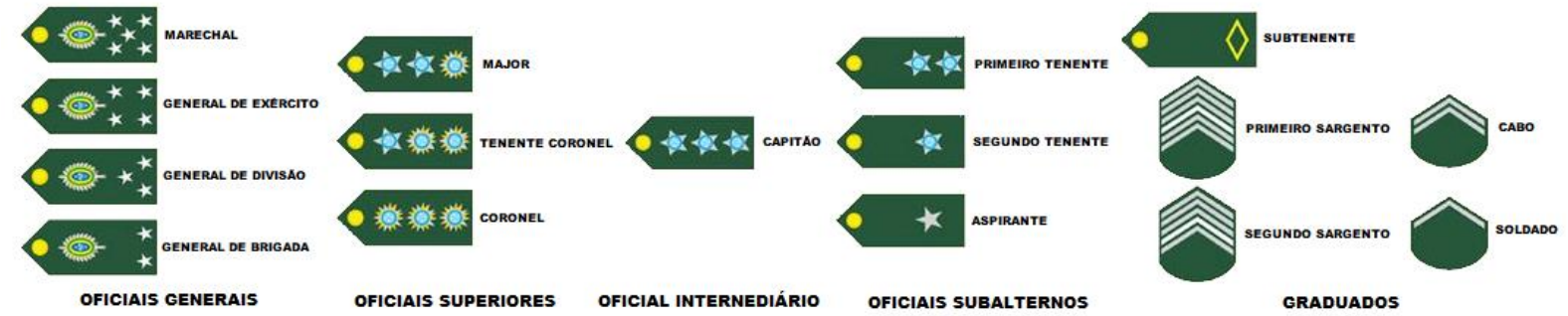

Fonte: Exército Brasileiro (n.d.).

A lei referida é a lei 4.375, de 17 de agosto de 1964 e seu conteúdo disserta acerca da forma pela qual ocorrerá a seleção dos brasileiros para a prestação do serviço militar, que obriga todos os brasileiros que sirvam ao Exército no ano em que completam 19 anos de idade (Brasil, n. d.). Ao ingressar por este modo, o indivíduo torna-se soldado e seu período de engajamento é de 12 meses. É possível, porém, prorrogar este período por até 7 anos, caso requerido pelo soldado, quando podem ser realizados cursos profissionalizantes e de ascensão, podendo tornar-se cabo, mediante aprovação e formação no Curso de Formação de Cabos (CFC) ou sargento, mediante aprovação e formação no Curso de Formação de Sargentos Temporários (CFST). O vínculo é renovado anualmente por interesse mútuo do indivíduo e da Instituição, e no fim do período, o militar é colocado na reserva nãoremunerada, de onde poderá ser convocado no caso de necessidade. Importante ressaltar que este processo somente pode ser feito por pessoas do sexo masculino, tendo em vista que a legislação supracitada isenta as mulheres de tal prestação.

A segunda forma de ingresso a ser referida é o ingresso em alguma das escolas militares, que será abordada neste estudo a partir do site do Governo Brasileiro (Brasil, n.d.). A Escola de Sargentos das Armas (EsSA) é a forma pela qual se formam sargentos de carreira que atuam no Exército Brasileiro. Após a aprovação em concurso público, o indivíduo, que pode ser homem ou mulher, deve passar por um período de formação na referida escola. Com a conclusão deste, o militar é promovido a 3o sargento. Ao longo de sua carreira, ele irá progredir hierarquicamente devido ao tempo de serviço e aos méritos alcançados, como a conclusão de cursos de especialização e realização de missões importantes. O posto máximo que pode atingido por esta categoria é o de capitão (Brasil, n. d.).

Já o ingresso na Escola Preparatória de Cadetes do Exército (EsPCEx) é o local onde inicia a formação de um oficial do Exército Brasileiro, também através de concurso público. Após o ingresso, o aluno passa por um período de adaptação de um ano nesta escola e, posteriormente, é transferido para a Academia Militar das Agulhas Negras (AMAN), localizada na cidade de Resende, RJ. Neste estabelecimento, a formação dura quatro anos e é finalizada com a ascensão ao posto de aspirante a oficial. (Brasil, n. d.). Findos o período em que o militar ainda não é estável, de seis meses, ele é promovido a segundo tenente. Assim como na formação dos sargentos, este indivíduo também progride hierarquicamente conforme o tempo e a meritocracia, sendo que a todo oficial é possibilitado atingir o posto de general. Aos militares cujo destaque tenha sido muito grande, é facultado à Presidência da República a promoção a general, mais alto posto em tempos de paz. 
Ainda, há outras formas de ingresso em que há menor abrangência quantitativa, como o Instituto Militar de Engenharia, o Quadro Complementar de Oficiais e a Escola de Saúde do Exército. Pode-se citar, ademais, os cursos de formação de militares temporários (Brasil, 2019c). Todavia, como o objetivo do estudo é analisar os militares de carreira, e não temporários, não será abordada com maior profundidade a forma de ingresso por tais métodos.

Por fim, considerando os objetivos deste artigo, é imprescindível abordar algumas características laborais que diferem os militares de outros servidores e trabalhadores dos setores público e privado. Conforme o site do Exército Brasileiro (n. d.), o militar está sob contínuo risco de vida; está sujeito a preceitos rígidos de disciplina e hierarquia; deve dedicarse exclusivamente ao Exército Brasileiro, ao longo das 24 horas do dia, sem reivindicar qualquer remuneração ou compensação; pode ser movimentado para qualquer região do país, podendo residir em locais inóspitos; e deve estar sempre preparado fisicamente, o que será atestado através de exames periódicos. Especialmente no que tange à legislação trabalhista, o militar é proibido de se sindicalizar e de participar em greves ou movimentos reivindicatórios. Ademais, apesar do militar rotineiramente trabalhar durante a noite e por um número elevado de horas, chegando a estar disponível por mais de uma semana continuamente, não há remuneração superior pelo trabalho noturno, bem como não há remuneração por horas extras.

Para realizar um paralelo com outros estudos organizacionais realizados com militares do Exército Brasileiro, algumas pesquisas serão mencionadas a seguir. Uma delas foi a dissertação elaborada por Miranda (2013) para traçar um perfil dos oficiais do EB, que demonstrou que cerca de $68 \%$ dos oficiais de até 10 anos de serviço militar pensa na possibilidade de mudar de carreira. Dentre os indivíduos que estão no período obrigatório de serviço até a aposentadoria somente metade deles está plenamente satisfeita com a carreira. Dentre os problemas do Exército e, por consequência, possíveis motivos para a insatisfação, estão os baixos salários, o pouco interesse do Congresso Nacional pelas questões militares e o orçamento inadequado.

Outra pesquisa que pode ser analisada refere-se à motivação no trabalho para oficiais do EB (Venturini, Pereira, Vey, Bornia, \& Reske Filho, 2007). Quando da realização do estudo, os principais fatores motivacionais para os respondentes foram, em ordem decrescente: a possibilidade de autorrealização, o conhecimento das políticas e missões do Exército Brasileiro, relacionamento geral, assunção de responsabilidades, comando e liderança competente, reconhecimento profissional, segurança e estabilidade na carreira, natureza do trabalho, tarefa ou missão, possibilidade de progresso na carreira militar e soldo e remuneração dos militares. Os dois estudos citados apresentam resultados incongruentes, já que Miranda (2013) percebeu os baixos salários como um fator de insatisfação, enquanto Venturini, Pereira, Vey, Bornia e Reske Filho (2007) apontam que o salário é o último dos fatores motivacionais. Ademais, é importante mencionar os principais valores e deveres esperados do militar do Exército Brasileiro, que podem ser observados na Tabela 1.

Tendo estes fatos em vista, torna-se importante entender o que trabalho significa para estes indivíduos que possuem ocupações tão distintas de outros setores da sociedade e quais suas motivações pessoais para o ingresso, mesmo considerando a redução de direitos trabalhistas a que estão submetidos. 
Sentido do trabalho e a escolha pela vida na caserna para militares do Exército Brasileiro

Tabela 1

Valores e deveres do Exército Brasileiro

\begin{tabular}{cc}
\hline Valores do Exército Brasileiro & Deveres do Exército Brasileiro \\
\hline Patriotismo & Dedicação e fidelidade à pátria \\
Civismo & Respeito aos símbolos nacionais \\
Amo missão do Exército & Probidade e lealdade \\
Espírito de corpo & Disciplina e respeito à hierarquia \\
Aprimoramento técnico-profissional & Rigoroso cumprimento dos deveres e ordens \\
\hline
\end{tabular}

Fonte: Elaborado pelos autores com base em Exército Brasileiro (n.d.).

Segundo Miranda (2013), há uma grande parcela dos militares que são "vocacionados", isto é, escolheram o Exército por vocação, enquanto muitos outros optaram por esta carreira pela estabilidade. Para o próprio Exército Brasileiro, em seu Vade Mecum de Cerimonial, contendo os valores, deveres e a ética militar, enuncia que

\begin{abstract}
A carreira militar não é uma atividade inespecífica e descartável, um simples emprego, uma ocupação, mas um ofício absorvente e exclusivista, que nos condiciona e autolimita até o fim. Ela não nos exige as horas de trabalho da lei, mas todas as horas da vida, nos impondo também nossos destinos. A farda não é uma veste, que se despe com facilidade e até com indiferença, mas uma outra pele, que adere à própria alma, irreversivelmente para sempre (EB, 2020c, p. 2).
\end{abstract}

No entanto, alguns questionamentos são relevantes: o que leva, então, um indivíduo a escolher este trabalho tão árduo e arriscado? Será que o trabalho é apenas uma ocupação ou realmente tem sentido? Tais perguntas serão aprofundadas a seguir.

\title{
3 ASPECTOS METODOLÓGICOS
}

Para a concretização do objetivo desta pesquisa, a saber, compreender o sentido trabalho para militares do Exército Brasileiro, optou-se pela metodologia quantitativa, que para Richardson (2011) caracteriza-se por abranger amostras mais amplas, propiciando dados mais exatos acerca do assunto pesquisado. Remete-se a pesquisa que emprega a quantificação tanto nas formas de coleta, quanto no tratamento de informações, aplicandose técnicas estatísticas (Michel, 2015).

Dessa maneira a abordagem quantitativa representa uma garantia de precisão nos resultados, evitando distorções de análise e interpretação, possibilitando uma margem de segurança. Ele se torna um meio para testar teorias, a partir da relação entre variáveis que podem ser medidas por instrumentos para analisar os dados de forma estatística (Richardson \& Pfeiffer, 2017). Com base nessa perspectiva, esse estudo utilizou como técnica de coleta de dados a aplicação de um instrumento de pesquisa denominado Escala do Trabalho com Sentido, elaborado por Morin e Dassa (2006) e adaptado para o português por Pedro Bendassolli e Jairo Borges-Andrade (2015). O questionário possui 24 itens que, em sua validação, possuíam Alphas de Cronbach entre 0,73 e 0,92. De acordo com Sampiere, Collado e Lucio (2013), quanto mais próximos de 1 os Alphas, maior a confiabilidade entre os indicadores. O instrumento de Bendassoli e Borges-Andrade (2015) tem por objetivo investigar, quantitativamente, o sentido do trabalho através de cinco dimensões, representadas no Tabela 2. 
Tabela 2

Dimensões do sentido do trabalho

\begin{tabular}{lr}
\hline \multicolumn{1}{c}{ Dimensões } & Descrição \\
\hline $\begin{array}{l}\text { Liberdade no trabalho (LIB) } \\
\text { Coerência e expressividade do } \\
\text { trabalho (CEE) }\end{array}$ & $\begin{array}{r}\text { Avalia a possibilidade de o indivíduo exercer seu julgamento para } \\
\text { resolver problemas e de tomar decisões com liberdade. }\end{array}$ \\
$\begin{array}{l}\text { Desenvolvimento e aprendizagem } \\
\text { que o sujeito desenvolveu a aos seus interesses profissionais e permite } \\
\text { que esse sujeito atinja seus objetivos e se faça ouvir. }\end{array}$ \\
$\begin{array}{l}\text { (DEA) } \\
\text { Qualidade das relações no }\end{array}$ \\
$\begin{array}{l}\text { Avalia a possibilidade oferecida pelo trabalho para as pessoas } \\
\text { trabalho (QUAL) } \\
\text { Utilidade social do trabalho (US) } \\
\text { Ética no trabalho (ET) }\end{array}$ \\
$\begin{array}{l}\text { Avalia existência de contatos interessantes no trabalho e o apoio dos } \\
\text { collegas. }\end{array}$
\end{tabular}

Fonte: Elaborado pelos autores com base em Bendassolli e Borges-Andrade (2011).

As dimensões do instrumento expostas na Tabela 2 podem ser relacionadas com alguns dos valores e deveres do Exército Brasileiro apresentados na Tabela 1, apresentando as seguintes conexões: a) patriotismo, civismo e dedicação e fidelidade à pátria relacionamse com a utilidade social do trabalho (US); b) espírito de corpo e respeito à hierarquia estão refletidos na qualidade das relações de trabalho; c) probidade e lealdade e trato do subordinado com dignidade revelam aspectos éticos que devem ser observados; e d) aprimoramento técnico-profissional engloba fatores das dimensões coerência e expressividade do trabalho e desenvolvimento e aprendizagem (EB 2020c; Bendassolli \& Borges-Andrade, 2011). Tal comparação, entre as dimensões do instrumento e os valores do $E B$, foi realizada a fim de demonstrar a aplicabilidade da escala no que tange ao contexto em que foi aplicada.

Cada questão do instrumento foi respondida de acordo com uma escala Likert de 6 pontos, sendo eles: 1 (extremamente em desacordo), 2 (bastante em desacordo), 3 (um pouco em desacordo), 4 (um pouco em acordo), 5 (bastante em acordo) e 6 (extremamente em acordo). Além destes itens, os participantes responderam oito itens relativos aos dados sociodemográficos.

Para o cálculo da amostra, adotou-se o critério proposto por Hair Jr. et al (2009), o qual estipula que a amostra mínima deve ser equivalente ao número de questões multiplicado por cinco, resultando em 120 questionários. A aplicação do instrumento foi realizada por meio da ferramenta Google Forms, dessa forma encaminhou-se o questionário aos contatos institucionais do Exército, bem como grupos laborais online por onde o público-alvo da pesquisa costuma se comunicar e, com isto, retornou um total de 166 respondentes. A delimitação da amostra abrangeu militares de carreira que prestaram concurso público para ingressar nas Forças Armadas, desconsiderando aqueles que cumprem serviço militar obrigatório e os que ocupam cargos temporários. Esta escolha deu-se a fim de pesquisar somente os indivíduos que escolheram seguir carreira efetiva nas Forças Armadas, que abrange os postos de 3 ㅇ sargento a general. A análise dos dados foi realizada através do software Microsoft Excel.

\section{APRESENTAÇÃO DOS RESULTADOS}

Inicialmente, será realizada a categorização da amostra de acordo com os dados sociodemográficos: gênero, idade, estado civil, escolaridade, existência de filhos ou não, posto no Exército Brasileiro, responsabilidade financeira pela família e tempo de atua ção na unidade em que labora atualmente. Identificou-se que a maioria dos respondentes são homens 
$(95,78 \%)$, entre 19 e 24 anos (30,72\%), casados $(50,60 \%)$, possuem ensino superior completo (46,39\%) e não possuem filhos $(69,28 \%)$.

O fato de poucas mulheres haverem participado da pesquisa deve-se, principalmente, ao fato de as mulheres ainda serem minoria na Instituição; elas ingressaram a partir de escolas de formação somente em 1992 e, em específico, na Escola Preparatória de Cadetes do Exército somente no ano de 2016 (EB, n. d.). No entanto, nas Diretrizes do Comandante do Exército, General Edson Leal Pujol, de 2019, uma preocupação é a consolidação da inserção das mulheres na linha de ensino militar bélico e a ampliação desta participação (EB, n. d.).

O posto predominante dos sujeitos da pesquisa é o de aspirante-a-oficial (28,9\%), sendo que, do total de respondentes, $38,55 \%$ são os únicos responsáveis pela renda família, seguido por $28,31 \%$ que são os principais responsáveis pela renda familiar. No que se refere ao tempo de serviços prestados, a maioria dos pesquisados $(49,40 \%)$ atuam por cerca de 1 a 4 anos na unidade militar em que estão servindo no presente momento, seguido por uma porcentagem de $21,69 \%$ que atua há menos de um ano e uma porcentagem de $21,69 \%$ que atua de 5 a 10 anos.

A Tabela 3 expõe os primeiros resultados da pesquisa. Foram calculados a média, o desvio padrão e o coeficiente de variação de cada uma das seis dimensões do instrumento da pesquisa, além de identificado o valor mínimo da soma das variáveis de cada uma das dimensões. Segundo Bendassolli e Borges-Andrade (2015), as médias são diretamente proporcionais ao quanto de sentido os indivíduos percebem em seus trabalhos, sendo que os autores apontam como parâmetros valores inferiores a 3,5 para escores baixos e superiores a 4,9 para escores altos, indicando, estes, uma alta percepção de sentido no trabalho.

Tabela 3

Estatística descritiva geral

\begin{tabular}{lcccccc}
\hline \multicolumn{1}{c}{ Dimensão } & Média & D. Padrão & Mínimo & C.V. (\%) & ANOVA* \\
\hline Qualidade das relações no trabalho (QUAL) & 5,44 & 0,76 & 16 & 13,98 & A \\
Utilidade social do trabalho (US) & 5,40 & 0,91 & 5 & 16,76 & A & \\
Desenvolvimento e aprendizagem (DEA) & 5,28 & 1,00 & 9 & 19,01 & A & B \\
Coerência e expressividade do trabalho (CEE) & 5,03 & 1,13 & 8 & 22,37 & C & B \\
Ética no trabalho (ET) & 4,95 & 1,22 & 6 & 24,70 & C & D \\
Liberdade no trabalho (LIB) & 4,45 & 1,24 & 4 & 27,85 & & D \\
\hline
\end{tabular}

Nota: * Letras diferentes na coluna diferem estatisticamente $(p<0,05)-$ Teste de Tukey.

Como é possível observar, utilizando os valores sugeridos pelos autores da escala, todas as médias foram de médias a altas, ou seja, superiores a 3,5. Os desvios padrões apresentaram valores aceitáveis, variando de 0,76 a 1,24, inferiores ao valor considerado elevado por Bendassolli e Borges-Andrade (2015), de 1,9.

No que tange aos valores mínimos somados em cada dimensão, houve uma grande variação, de 4 a 16 escores, manifestando que há disparidade na percepção de sentido do trabalho em relação a sua manifestação em forma de dimensões. Em todas as dimensões, o valor máximo apresentado pelos respondentes foi de 24 escores, motivo pelo qual este dado não está exposto na tabela; todavia, a partir desta constatação pode-se inferir que os benefícios relativos às dimensões são percebidos integralmente por parte da amostra.

Os valores dos coeficientes de variação são calculados a fim de fornecer dados sobre a dispersão dos resultados em relação à média, de forma que valores mais baixos denotam que a amostra é representativa, enquanto valores mais altos apontam a heterogeneidade entre os indivíduos. De acordo com Belfiore (2015), uma amostra pode ser considerada homogênea quando o valor do coeficiente de variação não ultrapassa 30\%. Martins e Domingues (2017) 
seguem nesta lógica, apontando que acima de $30 \%$ a dispersão é elevada, enquanto entre $15 \%$ e $30 \%$ é média e abaixo de $15 \%$ é baixa. Dessa forma, como todas as dimensões apresentaram coeficientes de variação aceitáveis, pode-se afirmar que a amostra é homogênea.

Por fim, foi realizado o teste de variância ANOVA, com o objetivo de verificar se os grupos são estatisticamente distintos. De acordo com este dado estatístico, médias seguidas das mesmas letras na coluna não diferem entre si. Assim, comparando as médias entre as dimensões, observou-se que as dimensões QUAL, US e DEA são estatisticamente iguais, ou seja, com valores acima de 5,28 (grupo A). Já a média da dimensão DEA é estatisticamente igual a CEE (grupo B). Esta, por sua vez, é estatisticamente igual a ET (grupo C) e, por fim, as duas menores médias, ET e LIB são estatisticamente iguais (grupo D).

Como maior média, é possível destacar a dimensão "qualidade das relações no trabalho", com um escore de 5,44 e um desvio padrão baixo, de 0,76. Ademais, a pontuação mínima nesta dimensão foi de 16 escores, um valor bastante elevado levando em consideração que o máximo seria de 24 pontos. A variável "Tenho boas relações com meus colegas de trabalho" foi a maior média do instrumento, com 5,57 escores.

Ademais, a dimensão "utilidade social do trabalho", pela sua alta média $(5,40)$, demonstrou que os respondentes acreditam que seus trabalhos são importantes para a sociedade, sendo possível inferir que os militares percebem que seus esforços pessoais fazem diferença para o Brasil, principalmente a partir da prática dos deveres institucionais de dedicação e fidelidade à pátria e dos valores de patriotismo e civismo. Os altos indicadores nas dimensões "desenvolvimento e aprendizagem" $(5,28)$ e "coerência e expressividade do trabalho" $(5,03)$ expõem que os militares entendem que o Exército Brasileiro valoriza suas competências e dá a oportunidade de aperfeiçoamento. A dimensão "ética no trabalho" também teve uma alta média $(4,95)$.

Destaca-se como menor média a dimensão "liberdade no trabalho", com um escore de 4,45. Aponta-se também que o desvio padrão foi o maior dentre os identificados, demonstrando que há certa disparidade entre os respondentes, possivelmente decorrente da maior ou menor autonomia concedidas pelo modelo hierárquico do EB. Nas variáveis desta dimensão, o item "Em meu trabalho, tenho liberdade para resolver os problemas de acordo com meu julgamento" apresentou a menor média de todo instrumento, de 4,16 escores.

Em seguida, o grupo de respondentes foi dividido em oficiais e praças - os oficiais correspondem aos postos de coronel, tenente coronel, major, capitão, 1 으 e 20 tenentes; os aspirantes-a-oficial são praças especiais que frequentam o círculo dos oficiais subalternos, de forma que foram enquadrados no grupo dos oficiais; por fim, os praças são os subtenentes, 1으, 2 e 3 sargentos. De acordo com Leite (2019), os oficiais são os indivíduos alocados em posições de comando, chefia e direção, enquanto os praças possuem papeis de execução e auxílio. Os dados estatísticos para oficiais e praças podem ser observados nas Tabelas 4 e 5 .

Tabela 4

Estatística Descritiva para Oficiais

\begin{tabular}{lcccccc}
\hline \multicolumn{1}{c}{ Dimensão } & Média & D. Padrão & Mínimo & C. V. (\%) & ANOVA* \\
\hline Qualidade das relações no trabalho (QUAL) & 5,57 & 0,70 & 16 & 12,57 & A \\
Utilidade social do trabalho (US) & 5,49 & 0,85 & 5 & 15,55 & A & \\
Desenvolvimento e aprendizagem (DEA) & 5,40 & 0,95 & 9 & 17,56 & A & B \\
Coerência e expressividade do trabalho (CEE) & 5,15 & 1,05 & 8 & 20,37 & & B \\
Ética no trabalho (ET) & 5,12 & 1,1 & 6 & 21,39 & & B \\
Liberdade no trabalho (LIB) & 4,58 & 1,20 & 4 & 26,30 & C &
\end{tabular}

* Letras diferentes na coluna diferem estatisticamente $(p<0,05)-$ Teste de Tukey. 
No caso dos oficiais, também se destacou positivamente a dimensão "qualidade das relações de trabalho", com a maior média e o menor desvio padrão, e negativamente a dimensão "liberdade no trabalho", com a menor média e maior desvio padrão. Quanto a análise comparativa observa-se que a "qualidade das relações no trabalho" dos oficiais é estatisticamente igual a "utilidade social do trabalho" e "desenvolvimento e aprendizagem" (Grupo A). Já as dimensões "desenvolvimento e aprendizagem", "coerência e expressividade do trabalho" e "ética no trabalho" dos oficiais são estatisticamente iguais (Grupo B). Finalmente, a "liberdade no trabalho" formou um grupo único com a menor média (Grupo C).

Ainda, identifica-se que todas as médias são superiores relativamente à amostra geral, enquanto todos os desvios padrões e todos os coeficientes de variação são inferiores - logo, pode-se inferir que os oficiais percebem maior sentido em seus trabalhos e suas opiniões são mais uniformes em relação aos seus pares. Em seguida, na Tabela 5, apresentam-se os dados para o grupo de praças.

Tabela 5

Estatística descritiva para praças

\begin{tabular}{|c|c|c|c|c|c|c|c|}
\hline Dimensão & Média & D. Padrão & Mínimo & C. V. (\%) & \multicolumn{3}{|c|}{ ANOVA* } \\
\hline Utilidade social do trabalho (US) & 5,26 & 0,98 & 8 & $18,54 \%$ & A & & \\
\hline Qualidade das relações no trabalho (QUAL) & 5,23 & 0,82 & 16 & $15,59 \%$ & $A$ & & \\
\hline Desenvolvimento e aprendizagem (DEA) & 5,06 & 1,06 & 9 & $20,91 \%$ & $A$ & B & \\
\hline Coerência e expressividade do trabalho (CEE) & 4,83 & 1,22 & 9 & $25,31 \%$ & A & B & $\mathrm{C}$ \\
\hline Ética no trabalho (ET) & 4,66 & 1,37 & 9 & $29,39 \%$ & & B & $\mathrm{C}$ \\
\hline Liberdade no trabalho (LIB) & 4,23 & 1,27 & 7 & $30,01 \%$ & & & $\mathrm{C}$ \\
\hline
\end{tabular}

* Letras diferentes na coluna diferem estatisticamente $(p<0,05)-$ Teste de Tukey.

Ao contrário dos oficiais, as médias do grupo de praças foram todas inferiores e os desvios padrão e coeficientes de variação foram superiores à amostra geral. Houve também diferença em relação às dimensões que se destacaram. A maior média foi relativa à dimensão "utilidade social do trabalho". Isto pode ser explicado pelo fato de os praças possuírem maior contato com a tropa, isto é, com os soldados que ingressam anualmente no Exército Brasileiro, já que são tidos como "o elo fundamental entre o comando e a tropa", além de terem tido valorização da carreira com algumas alterações em sua formação ocorridas recentemente, como o reconhecimento pela qualificação (Barbosa, 2019).

A menor média seguiu sendo a "liberdade no trabalho", porém o coeficiente de variação neste aspecto foi de $30,01 \%$, podendo-se afirmar, pois, que a percepção de sentido do trabalho através da liberdade é bastante variada entre o público de praças. Pode-se observar, outrossim, que a dimensão "coerência e expressividade do trabalho" apresentou escore mediano $(4,83)$ conforme os autores do instrumento, assim como a dimensão "ética no trabalho" $(4,66)$. Assim, percebe-se que três das seis dimensões apontam a percepção regular de sentido do trabalho, enquanto a outra metade demonstra índices mais altos de sentido do trabalho.

Comparando estatisticamente as médias entre as dimensões, para os praças, a US é estatisticamente igual QUAL e DEA (Grupo A). Ainda, o DEA é estatisticamente igual a CEE e a ET (Grupo B). O último grupo é comporto por CEE, ET e LIB, que são estatisticamente iguais (Grupo C). A seguir, os dados obtidos serão discutidos.

\section{DISCUSSÃO DOS RESULTADOS}

Como maior média da amostra, é possível destacar a dimensão "qualidade das relações no trabalho". Isto demonstra que a maior parte dos respondentes possui uma boa 
relação com os companheiros de trabalho, não havendo grandes disparidades entre as respostas. Em sua tese, Juliane Umann (2017) enuncia que desenvolver medidas de suporte social no âmbito do Exército, como as boas relações entre colegas, é importante para alavancar o ganho de resiliência e a redução de estresse, melhorando a saúde dos trabalhadores. Neste estudo, a autora concluiu, ainda, que os militares demonstram altos níveis de resiliência, baixos níveis de estresse e boa capacidade para o trabalho.

Em relação aos altos indicadores nas dimensões "desenvolvimento e aprendizagem" e "coerência e expressividade do trabalho, é importante mencionar que a meritocracia é um fator relevante para a tomada de decisões na Instituição, a exemplo de uma das diretrizes do Comandante do Exército para o ano de 2019 - "aperfeiçoar a gestão de pessoal no âmbito do Exército, prosseguindo no aprimoramento do fluxo de carreira dos oficiais e graduados, ampliando a meritocracia nos processos de promoção" (EB, 2020b, p. 15). Ainda, o aperfeiçoamento dos militares é feito, no Exército, através da melhoria contínua por meio de cursos de especialização e modernização e estágios, o que justifica a percepção de sentido por meio das dimensões indicadas.

Acerca da dimensão "ética no trabalho", que obteve uma média alta, observa-se que este é um valor bastante cultuado no EB e, institucionalmente, a ética militar divide-se em sentimento do dever, honra pessoal, pundonor militar e decoro da classe; as falhas éticas são consideradas graves e, em muitos casos, constituem crime ou transgressão militar e são apreciadas para a evolução da carreira (EB, 2020c). Sobre a menor média ter ocorrido na dimensão "liberdade no trabalho", entende-se esse resultado em decorrência de o Exército ter finalidade pública e ter a estrutura baseada na hierarquia e na disciplina. Dessa forma, o motivo de a dimensão relacionada à liberdade apresentar os menores índices pode ser compreendido.

Apesar de verem sentido em seus trabalhos, isto não significa que há total satisfação, tendo em vista que as pesquisas de Venturini et al. (2007) e Miranda (2013) demonstraram falta de satisfação em uma parcela da população militar. No entanto, o Exército Brasileiro já vem somando esforços no sentido de melhores práticas de recursos humanos. Em decorrência da necessidade de uma reestruturação, iniciou-se um Processo de Transformação baseado em pilares, como o fortalecimento da dimensão humana. Nesse sentido, o programa "Força da Nossa Força" tem como propósitos a valorização da força de trabalho, a melhoria da qualidade de vida da Família Militar, a modernização da gestão de pessoal, entre outros. Tais ações relacionam-se à máxima "atrair, reter, motivar e comprometer" (EB, n.d.).

A Figura 2 apresenta visualmente as diferenças entre as médias obtidas na amostra geral, no grupo de oficiais e no grupo de praças.

Figura 2

Comparativo entre as médias de oficiais e praças

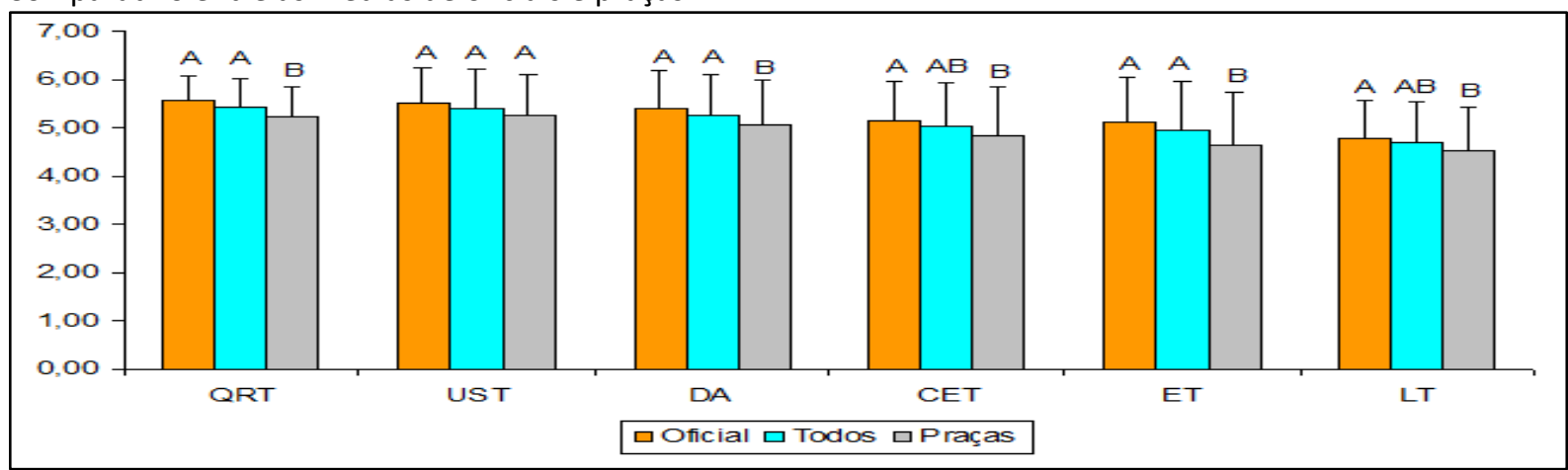

Nota: * Letras diferentes na coluna diferem estatisticamente $(p<0,05)-$ Teste de Tukey 
Nesse sentido, é possível perceber que todas as médias foram menores no grupo de praças e maiores nos grupos de oficiais, com a maior variação na dimensão "ética no trabalho", com uma diferença de 0,46 escores (9,87\%). Analisando as diferenças estatísticas observa-se que a única dimensão que os três grupos não diferiram estatisticamente foi a "utilidade social do trabalho" ( $p>0,05)$; nas demais, os oficiais diferiram estatisticamente para maior em relação aos praças.

O item com menor média de todo o instrumento para os praças foi a afirmativa "Trabalho em um ambiente em que todos são tratados com igualdade", com 4,0 escores, contra 4,91 dos oficiais. A falta de estudos que tratem sobre esta temática e o pouco aprofundamento subjetivo deste estudo quantitativo não permitem entender o motivo desta disparidade, porém como a dimensão objetiva avaliar a existência de justiça e equidade no trabalho, há a possibilidade de que a posição inferior na cadeia hierárquica e a compreensão de igualdade possam interferir nessa percepção.

Com isso, é possível afirmar com base no exposto que os oficiais veem mais sentido em seus trabalhos do que os praças, já que cerca de $83 \%$ das dimensões relativas aos oficiais demonstraram elevada percepção de sentido do trabalho, enquanto apenas $50 \%$ da dimensões relativas ao trabalho dos praças demonstrou o mesmo. Entretanto, as disparidades não foram muito significativas, tendo em vista que a maior diferença entre os grupos foi de 9,87\% na dimensão "ética no trabalho". Assim, em termos gerais, pode-se afirmar que os militares do Exército Brasileiro veem bastante sentido em seus trabalhos, de acordo com a Escala de Trabalho com Sentido.

\section{CONSIDERAÇÕES FINAIS}

Este artigo buscou compreender o sentido do trabalho para os militares do Exército Brasileiro, a partir da aplicação de questionários de forma online em militares de carreira no ano de 2020. Frente a grande visibilidade que a Instituição teve após a eleição de antigos militares aos cargos de Presidente e Vice-Presidente da República, além da notoriedade que algumas missões desempenhadas pelo Exército tiveram, torna-se relevante discutir sobre a Instituição e seu papel para a manutenção do Estado Brasileiro, conhecendo seu funcionamento e especificidades, como o trabalho desempenhado pelos militares, que os diferem de inúmeras categorias de trabalhadores. Além de possuírem um regime jurídico diferente, que não permite o pagamento de horas extras e adicional noturno, a carreira militar está relacionada fortemente à abnegação em prol do Brasil, logo identificar o sentido que os indivíduos que optaram por segui-la dão aos seus trabalhos é também entender a motivação daqueles que defendem o território brasileiro, sua soberania e sociedade.

Optou-se pela aplicação da Escala do Trabalho com Sentido, elaborada por Bendassolli e Borges-Andrade, que possui seis dimensões: liberdade no trabalho, coerência e expressividade do trabalho, desenvolvimento e aprendizagem, qualidade das relações no trabalho, utilidade social do trabalho e ética no trabalho. Os questionários foram enviados através de grupos de comunicação entre militares e obteve-se uma amostra de 166 respondentes, todos eles militares de carreira, variando seus postos entre 3은 Sargento e Coronel.

Com a análise dos dados obtidos, identificou-se que os militares da amostra veem elevado sentido em seus trabalhos, principalmente a partir da existência de contatos interessantes no trabalho e o apoio dos colegas, característica que ilustra o espírito de camaradagem e de corpo que está entre os valores do Exército Brasileiro (EB, 2020c). As 
demais dimensões, "coerência e expressividade do trabalho", "utilidade social do trabalho", "desenvolvimento e aprendizagem" e "ética no trabalho" também apresentaram bons índices, variando de 4,95 a 5,40 escores. Tal aspecto demonstra que os militares, em geral, percebem bastante sentido em seus trabalhos, o que, segundo Bendassolli e Borges-Andrade (2015), propicia o desenvolvimento psicológico dos indivíduos, bem como seu bem-estar e sua satisfação.

A dimensão que se destacou negativamente foi a "liberdade do trabalho", que avalia a possibilidade de o indivíduo exercer seu julgamento para resolver problemas e de tomar decisões com liberdade. Tendo em vista a estrutura baseada na hierarquia e na disciplina, tal resultado não é inesperado. Dentre os deveres do militar, está justamente o rigoroso cumprimento dos deveres e ordens. No entanto, o próprio Exército Brasileiro aponta que a disciplina não deve ser imposta, e sim consciente. É claro que isto é um processo bastante complexo, pois envolve uma relação de confiança mútua entre subordinados e seus superiores, porém sugere-se a realização de ações de sensibilização dos colaboradores para que entendam os limites de sua autonomia não como cerceamento de sua liberdade, mas como uma distribuição e compreensão dos direitos e deveres de cada militar.

Quando analisados separadamente, os oficiais e praças apresentaram resultados diferentes. Enquanto os oficiais obtiveram maiores médias do que a amostra geral, os praças obtiveram resultados mais baixos em todas as dimensões, com a maior diferença entre os grupos na dimensão "ética no trabalho". Pela falta de referenciais teóricos que abordem aspectos relativos ao comportamento organizacional no Exército Brasileiro, não foi possível identificar o motivo desta diferença entre os indivíduos, de forma que se sugere que este estudo seja aprofundado para incluir um viés qualitativo, de maior subjetividade, através da realização de entrevistas ou grupos focais, por exemplo. Isto possibilitaria perceber aspectos mais intangíveis do sentido do trabalho para esta população, tendo em vista que os métodos quantitativos limitam a compreensão deste tipo de fenômeno. Ainda, para futuros estudos, sugere-se que a amostra seja ampliada para um maior número de respondentes, por meio da dispersão de questionários através de formas de comunicação internas do Exército Brasileiro.

Tendo isto em consideração, os esforços empenhados na pesquisa podem se constituir em benefícios para a instituição estudada, considerando que a compreensão sobre a percepção do sentido do trabalho para os militares do Exército Brasileiro pode servir como base para desenvolver ações de melhoria no trabalho, especialmente no que tange à diferença entre oficiais e praças. Por fim, cumpre salientar que a compreensão do sentido do trabalho para militares do Exército Brasileiro pode contribuir para a discussão acerca da forma pela qual se comporta esta categoria. Como o EB é uma peça fundamental para garantir a proteção e a soberania brasileiras, pensar no bem-estar de seus servidores é importante para permitir que seus trabalhos sejam executados cada vez com maior excelência.

\section{REFERÊNCIAS}

Barbosa, J. (2019). Sargento: o elo cada vez mais forte entre o comando e a tropa. Blog do Exército Brasileiro. http://eblog.eb.mil.br/index.php/menu-easyblog/sargento-o-elocada-vez-mais-forte-entre-o-comando-e-a-tropa.html.

Belfiore, P. (2015) Estatística aplicada a administração, contabilidade e economia com Excel e SPSS. Rio de Janeiro: Elsevier. 
Bendassolli, P. F. \& Borges-Andrade, J. E. (2011). Significado do trabalho nas indústrias criativas. Revista de Administração de Empresas, 51 (2), 143-159. https://doi.org/10.1590/S0034-7590201100020000.

Brasil. (1988). Constituição Federal de 1988. Brasília: Senado Federal, 1988. http://www.planalto.gov.br/ccivil_03/Constituicao/Constituiçao.htm.

Brasil. (1964). Lei n. 4.375, de 17 de agosto de 1964. Lei do serviço militar. Brasília: EstadoMaior das Forças Armadas. http://www.planalto.gov.br/ccivil_03/LEIS/L4375.htm.

Brasil. (n. d.). Saiba como ingressar e seguir a carreira militar no Exército. http://www.brasil.gov.br/noticias/seguranca-e-justica/2014/06/saiba-como-ingressare-seguir-a-carreira-militar-no-exercito.

Codo, W. (1997). Um diagnóstico do trabalho (em busca do prazer). In: Tamayo, J., BorgesAndrade, J. E. \& Codo, W. (Eds.). Trabalho, organizações e cultura, p. 21-40. São Paulo: Cooperativa de Autores Associados.

Silva, M. (2019). A importância do Exército Brasileiro ao longo da história política do Brasil: de sua criação até os dias atuais. Monografia (Especialização em Ciências Militares), Escola de Aperfeiçoamento de Oficiais, Rio de Janeiro, RJ, Brasil.

Dejours, C. (1987). A loucura do trabalho. São Paulo, SP: Oboré.

Santos, E. (2018). Exército brasileiro: a transformação como valor e o valor da transformação. [Tese de Doutorado, Pontifícia Universidade Católica do Rio de Janeiro]. Repositório da Pontifícia Universidade Católica do Rio de Janeiro. https://doi.org/10.17771/PUCRio.acad.34898.

Exército Brasileiro. (n.d.). A história da mulher no Exército Brasileiro. http://www.eb.mil.br/web/ingresso/mulheres-no-exercito//asset_publisher/6ssPDvxqEURI/content/a-historia-da-mulher-no-exercito.

Exército Brasileiro. (n.d.). Características da profissão militar. http://www.eb.mil.br/caracteristicas-da-profissao-militar.

Exército Brasileiro. (n.d.). Conhecendo o programa Força da Nossa Força. http://www.dgp.eb.mil.br/index.php/ultimas-noticias1/190-conhecendo-o-programaforca-da-nossa-forca.

Exército Brasileiro. (n.d.). Diretrizes do Comandante do Exército 2019. http://www.eb.mil.br/documents/10138/9474894/DIRETRIZ+DO+COMANDANTE+DO+ EX\%C3\%89RCITO+2019+OTIMIZADO.pdf/eca42421-8af4-ddfa-e94a-0572f280c37b.

Exército Brasileiro. (n.d.). Missão e visão de futuro do exército brasileiro. http://www.eb.mil.br/missao-e-visao-de-futuro. 
Exército Brasileiro. (n.d.). Postos e graduações. http://www.eb.mil.br/postos-e-graduacoes.

Exército Brasileiro. (n.d.). Vade Mécum de cerimonial militar do Exército - valores, deveres e ética militar.

http://www.eb.mil.br/documents/10138/6563889/Vade+M\%C3\%A9cum+Valores.pdf.

Hackman, J. \& Oldhan, G. (1975). Development of job diagnostic survey. Journal of Applied Psychology, 60 (2), 159-170.

Hair, J. F., Black, W. C., Babin, B. J., Anderson, R. E., \& Tatham, R. L. (2009). Análise multivariada de dados. São Paulo: Bookman.

Leite, C. (2019). As transformações do Exército Brasileiro na sociedade contemporânea: do individualismo moderno ao hiperindividualismo pós-moralista. [Tese de doutorado, Universidade do Vale do Rio dos Sinos]. Repositório da Universidade do Vale do Rio dos Sinos. http://www.repositorio.jesuita.org.br/handle/UNISINOS/8720.

Leirner, P. (1997). Meia volta-volver: um estudo antropológico da hierarquia militar. Rio de Janeiro: Editora FGV.

Luchetti, M. (2006). O ensino no exército brasileiro: histórico, quadro atual e reforma. [Dissertação de mestrado, Universidade Metodista de Piracicaba]. Repositório da Universidade Metodista de Piracicaba.

http://iepapp.unimep.br/biblioteca_digital/visualiza.php?cod=MTUw.

Magalhães, J. (1998). A evolução militar do Brasil (2a ed.). Rio de Janeiro: Biblioteca do Exército.

Martins, G., \& Domingues, O. (2019). Estatística geral e aplicada (6a ed.). São Paulo: Atlas.

Marx, K. (1993). Os manuscritos econômicos e filosóficos. v. 22. Textos filosóficos. Lisboa, Portugal: Edições 70.

Mendes, L. \& Santos, F. S (2013). Os sentidos e significados no trabalho de controlador aéreo. Psicologia \& Sociedade, 25 (3), 706-717. https://doi.org/10.1590/S010271822013000300024.

Michel, M. H. (2015) Metodologia e pesquisa científica em ciências sociais: um guia prático para acompanhamento da disciplina e elaboração de trabalhos monográficos (3a ed.). São Paulo: Atlas.

Miranda, D. (2013). A construção da identidade do oficial do Exército Brasileiro. [Dissertação de Mestrado, Pontifícia Universidade Católica do Rio de Janeiro]. Repositório da Pontifícia Universidade Católica do Rio de Janeiro. https://doi.org/10.17771/PUCRio.acad.21902. 
Morin, E. (1996). La quête du sens au travail. Congrès international de l'Association de Psychologie du travail de langue française. Sherbrooke, France: Université de Sherbrooke.

Morin, E. (2001). Os sentidos do trabalho. Revista de Administração de Empresas, 41 (3), 819. http://dx.doi.org/10.1590/S0034-75902001000300002.

Morin, E. \& Aubé, C. (2009). Psicologia e gestão. São Paulo: Atlas.

Morin, E. \& Dassa, C. (2006). Characteristics of a meaningful work. Montréal: HEC.

Meaning of Work International Research Team. (1987). The meaning of working. London: Academic Press.

Oliveira, S. R., Piccinini, V. C., Fontoura, D. S., \& Schweig, C. (2004). Buscando o sentido do trabalho [Comunicação oral]. XXVIII Encontro da Associação Nacional de PósGraduação e Pesquisa em Administração, Porto Alegre, RS, Brasil.

Richardson, R. J. (2011). Pesquisa Social: métodos e técnicas. São Paulo: Atlas.

Richardson, R.; Pfeiffer, D. (2017). Pesquisa social: métodos e técnicas [4a ed.]. São Paulo: Atlas.

Rohm, R. \& Lopes, N. (2015). O novo sentido do trabalho para o sujeito pós-moderno: uma abordagem crítica. Cadernos EBAPE.BR, 13 (2), 332-345. https://doi.org/10.1590/1679395117179.

Sousa, V. A. (2012). As transformações do mundo do trabalho. Revista Aurora, 5, 25-36.

Tavares, A. (1985). Nosso exército: essa grande escola. Rio de Janeiro: Biblioteca do Exército.

Tolfo, S. da R. \& Piccinini, V. (2007). Sentidos e significados do trabalho: explorando conceitos, variáveis e estudos empíricos brasileiros. Psicologia \& Sociedade, 19, 38-46. https://doi.org/10.1590/S0102-71822007000400007.

Venturini, J.; Pereira, B.; Vey, I.; Bornia, A.; \& Reske Filho, A. (2007). Motivação no trabalho dos oficiais do Exército Brasileiro: um estudo de caso [Comunicação oral]. XXVII Encontro Nacional de Engenharia de Produção, Foz do Iguaçú, PR, Brasil. 